MagNetE workshop 2011

\title{
Comparison of the reference mark azimuth determination methods
}

\author{
Danijel Šugar ${ }^{\star}$, Mario Brkić, Drago Špoljarić
}

University of Zagreb, Faculty of Geodesy, Zagreb, Croatia

\section{Article history}

Received September 30, 2011; accepted April 18, 2012.

Subject classification:

Satellite geodesy, Geodetic (ellipsoidal) azimuth, Astronomic azimuth, Repeat station, Reference mark, GNSS, CROPOS.

\begin{abstract}
The knowledge of the azimuth of the reference mark is of crucial importance in the determination of the declination which is defined as the ellipsoidal (geodetic) azimuth of the geomagnetic meridian. The accuracy of the azimuth determination has direct impact on the accuracy of the declination. The orientation of the Declination-Inclination Magnetometer is usually carried out by sighting the reference mark in two telescope faces in order to improve the reliability of the observations and eliminate some instrumental errors. In this paper, different coordinate as well as azimuth determination methods using GNSS (Global Navigation Satellite System) observation techniques within VPPS (High-Precision Positioning Service) and GPPS (Geodetic-Precision Positioning Service) services of the CROPOS (CROatian POsitioning System) system were explained. The azimuth determination by the observation of the Polaris was exposed and it was subsequently compared with the observation of the Sun using hourangle and zenith-distance method. The procedure of the calculation of the geodetic azimuth from the astronomic azimuth was explained. The azimuth results obtained by different methods were compared and the recommendations on the minimal distance between repeat station and azimuth mark were given. The results shown in this paper were based on the observations taken on the POKU_SV repeat station.
\end{abstract}

\section{Introduction}

The knowledge of the azimuth of the reference mark is of crucial importance in the determination of the geomagnetic declination. According to the definition, the geomagnetic declination is the angle between the geographic north direction and the magnetic meridian [Jankowski and Sucksdorff 1996] i.e. the ellipsoidal (geodetic) azimuth of the magnetic meridian. There are several azimuth determination methods: it can be calculated upon known geodetic coordinates of the station and target point (reference mark), by methods of geodetic astronomy, by usage of gyro-theodolite as well as by modern GNSS (Global Navigation Satellite System) methods. In this paper is given an overview and comparison of the determination of azimuth by GNSS methods within the CROPOS (Croatian Positioning System) system as well as by the astronomic methods. The determination of azimuth by gyro-theodolite hasn't been discussed in detail because such an instrument wasn't available for the survey on the field.

\section{Azimuth determination by GNSS methods}

The GNSS today includes different global satellite navigation and positioning systems: American GPS (Global Positioning System), Russian GLONASS (GLObalnaya NAvigatsionnaya Sputnikovaya Sistema), European Galileo and in future many other systems. Generally, GNSS uses two basic positioning methods: absolute and relative. Absolute method provides the coordinates with lower precision and therefore it is used in navigation, while the relative methods provide higher precision of the coordinates and are used for positioning. Furthermore, positioning methods are classified as static or kinematic depending whether the GNSS receiver during the observations was stationary or roving. Such two positioning methods (static relative and kinematic relative) were applied in this paper for the determination of the coordinates and subsequent calculation of the ellipsoidal azimuth. Both methods require at least two GNSS receivers simultaneously observing the same satellites in order to allow the computation of the baseline vectors between receivers (stations). Using the static relative method the baseline vectors are obtained in post-processing, while using the relative kinematic method with ambiguity resolution in real time (RTK, Real Time Kinematic) the coordinates are determined directly on the field. The unknown coordinates of the station can be determined by adding the processed baseline vectors to the known coordinates of the reference station. If at several stations with known coordinates the baseline vectors towards an unknown station were processed then the coordinates of the unknown station can be determined by the least-squares adjustment procedure [Hofmann-Wellenhof et al. 2008].

\subsection{GNSS observations during the CGRSN setup}

During the setup and survey of the CGRSN (Croatian Geomagnetic Repeat Stations Network) in 2004, the coordinates were determined by static relative positioning method [Brkić et al. 2006]. Three Trimble 4000 SSi GPS receivers 
were simultaneously used for GPS observations: two receivers at reference stations with known coordinates, one receiver at new geomagnetic repeat station and corresponding reference marks. Upon the baseline vectors processing and network adjustment the coordinates were determined in the reference system of the known coordinates (ETRS89). The European Terrestrial Reference System 1989 (ETRS89) is an ECEF (Earth-Centered, Earth-Fixed) geodetic Cartesian reference frame, in which the Eurasian Plate as a whole is considered static. The coordinates and maps in Europe based on ETRS89 are not subject to change due to the continental drift (http:/ / etrs89.ensg.ign.fr/). At the time of the CGRSN setup and survey the ETRS89 was not the officially accepted national reference system, so the coordinates were transformed into the Croatian State Coordinate System (CSCS). The model of seven-parameter Helmert's transformation with parameters valid for the territory of the Zagreb County was used for the transformation of the coordinates. In order to improve the transformation accuracy, the geoid surface was used [Bašić 2009]. After the coordinate transformation from ETRS89 and associated ellipsoid GRS80 (Geodetic Reference System 1980) to CSCS and associated Bessel-1841 ellipsoid, the plane coordinates were computed in Transverse Mercator projection. The main property of that projection is its conformity meaning that the projection of the rotational ellipsoid into the plane is free from angle deformation. The grid azimuth from the repeat station to the reference mark was calculated from the plane coordinates. In addition to the grid azimuth, the convergence of the meridian was calculated for the repeat station and by adding it to the grid azimuth, the ellipsoidal (geodetic) azimuth was obtained. In the ellipsoidal azimuth computation the correction for curvature of the geodesic was neglected because of its small amount. Of course, the ellipsoidal azimuth could be computed from the ellipsoidal coordinates of the repeat station and reference mark (for example using the Clarke method), but the computations from plane coordinates were much easier and quicker. The ellipsoidal azimuth calculated from plane coordinates was used for DIM (Declination-Inclination Magnetometer) orientation and the subsequent observations of geomagnetic declination. The Transverse Mercator projection plane coordinates of the repeat station as well as the reference mark at POKUpsko location, along with grid azimuth, convergence of the meridian and ellipsoidal azimuth are given in Table 1.

\subsection{GNSS observations today - CROPOS system}

In August 2004 the Croatian Government introduced the new official geodetic datums. As the new positional geodetic reference system the ETRS89 was adopted i.e. its realization ETRF89. The European Commission has recommended the adoption of ETRS89 as the geodetic datum for geo-referenced information and has promoted the use of ETRS89 within its member states (http:/ / www.euref.eu/euref_egrs.html). In comparison to the older CSRS which is a local geodetic system, the ETRS89 is a global system facilitating the application of the GNSS in geodetic practice in Croatia. A further important step in GNSS application took place at the end of 2008 with the establishment of the CROPOS (CROatian POsitioning System) system. CROPOS is the state GNSS reference network consisting of 30 CORS (Continuously Operation Reference Station) stations evenly distributed over the national territory at the average distance of $70 \mathrm{~km}$. At each reference station the GPS and GLONASS satellites are observed, observations are sent to the computing centre where the data are checked, processed, modeled and adjusted in order to get a networked solution [Marjanović 2010]. The coordinates of the CORS stations were precisely determined in ITRF2005 (International Terrestrial Reference Frame) and subsequently transformed in ETRF2000 (R05) (http:/ / www.cropos.hr/

\begin{tabular}{|c|c|c|c|c|c|}
\hline Station & $\mathbf{y}(\mathbf{m})$ & $\mathbf{x}(\mathbf{m})$ & Grid azimuth (DMS) & $\begin{array}{l}\text { Convergence of } \\
\text { meridian (DMS) }\end{array}$ & $\begin{array}{c}\text { Ellipsoidal azimuth } \\
\text { (DMS) }\end{array}$ \\
\hline POKU_SV & 5576879.548 & 5036993.908 & $359^{\circ} 00^{\prime} 11.7^{\prime \prime}$ & $0^{\circ} 42^{\prime} 04.0^{\prime \prime}$ & $359^{\circ} 42^{\prime} 15.7^{\prime \prime}$ \\
\hline POKU_GOT2 & 5576869.417 & 5037576.209 & & & \\
\hline
\end{tabular}

Table 1. Plane coordinates $(\mathrm{y}, \mathrm{x})$ and the ellipsoidal azimuth of the POKU_SV repeat station and the reference mark POKU_GOT2 (y-north direction, $\mathrm{x}$-east direction).

\begin{tabular}{ccccc}
\hline CROPOS service & Solution method & Transfer of data & Accuracy & Data format \\
GPPS & post-processing & Internet (FTP, e-mail) & $1 \mathrm{~cm}(2 \mathrm{D}, 3 \mathrm{D})$ & RINEX \\
VPPS & $\begin{array}{c}\text { Network solution of phase } \\
\text { measurements in real time }\end{array}$ & $\begin{array}{c}\text { Wireless Internet } \\
\text { (GPRS/UMTS), NTRIP } \\
\text { protocol, GSM }\end{array}$ & $2 \mathrm{~cm}(2 \mathrm{D}) ; 4 \mathrm{~cm}(3 \mathrm{D})$ & RTCM \\
\hline
\end{tabular}

Table 2. Main characteristics of the CROPOS GPPS and VPPS services (http: / / www.cropos.hr/index.php?option=com_content\&view=article\&id=14\& Itemid=9\&lang=en). 

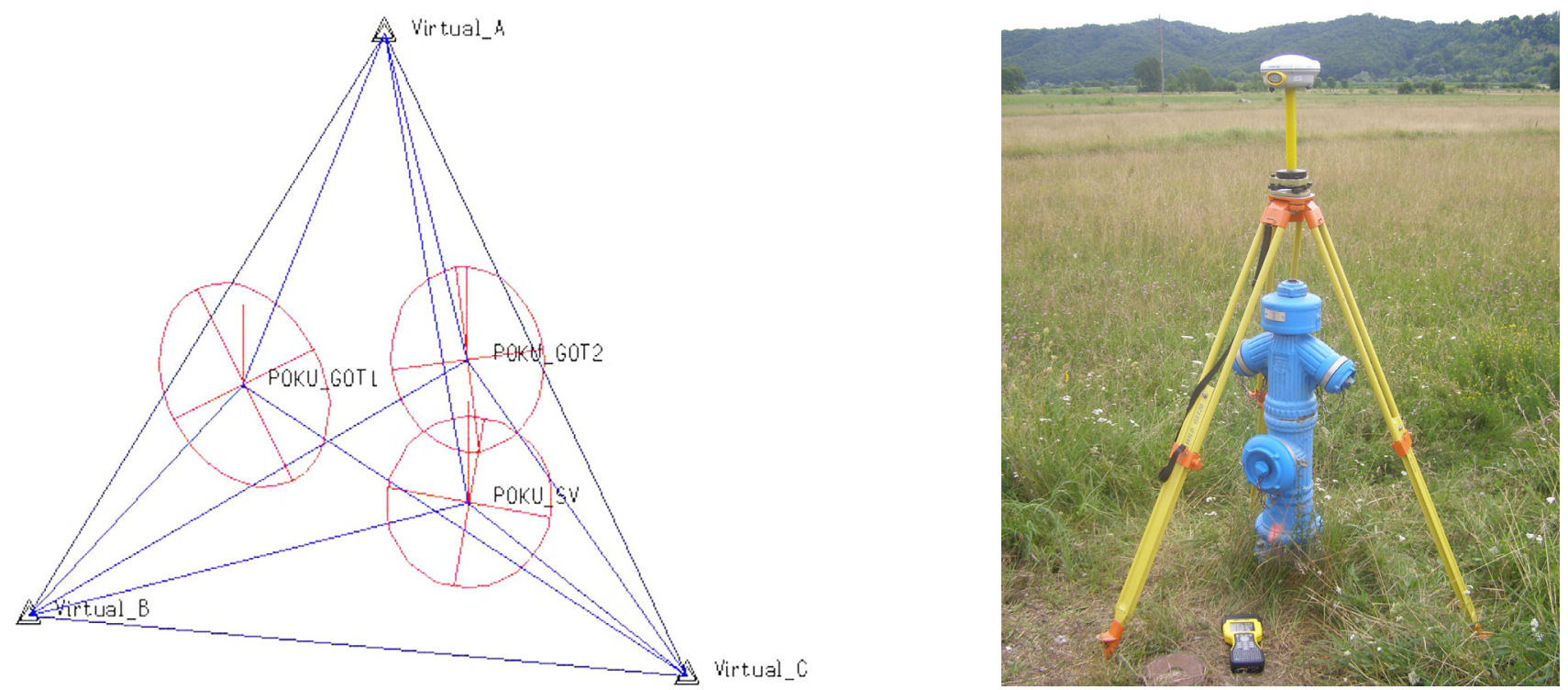

Figure 1. GNSS network with the error ellipses (left); GNSS receiver observing on the reference mark (right).

\begin{tabular}{ccccc}
\hline Station & Latitude $($ DMS $)$ & Northing precision $(\mathbf{m})$ & Longitude $($ DMS $)$ & Easting precision $(\mathbf{m})$ \\
POKU_SV & $45^{\circ} 28^{\prime} 22.91664^{\prime \prime}$ & 0.005 & $15^{\circ} 58^{\prime} 42.66654^{\prime \prime}$ & 0.005 \\
POKU_GOT2 & $45^{\circ} 28^{\prime} 41.78152^{\prime \prime}$ & 0.005 & $15^{\circ} 58^{\prime} 42.52674^{\prime \prime}$ & 0.004 \\
\hline
\end{tabular}

Table 3. Ellipsoidal coordinates with their precisions (GPPS).

index.php?option $=$ com_content $\&$ view $=$ section $\&$ layout $=$ blog\&id=1\&Itemid $=2$ \&lang $=$ en) which is today the conventional frame of the ETRS89 system (http: / / etrs89.ensg. ign.fr/memo-V8.pdf). The CROPOS system provides three services, but only two services used in azimuth determination were considered: GPPS (Geodetic Precise Positioning Service) and VPPS (Highly Precise Positioning Service). The GPPS service is used for static relative positioning providing 1-cm positional accuracy, while the VPPS service is used for RTK applications providing 2 - $\mathrm{cm}$ positional accuracy. The main characteristics of both services are given in Table 2 .

\subsubsection{The application of GPPS service in azimuth determination}

With GPPS service there is no need for several GNSS receivers observing at stations with known coordinates, only one receiver is required for the observations on the station with unknown coordinates. The data files with satellite observations at CORS stations can be downloaded in the RINEX (Receiver Independent Exchange Format) format from the CROPOS Web server (http://195.29.118.122/). In addition to CORS station data, the data can be downloaded for any VRS (Virtual Reference Station), preferably in the vicinity of the station which coordinates are to be determined. The usage of VRS data enables considerably shorter station occupation with insignificant loss of precision in comparison to the usage of data from CORS stations [Šugar et al. 2009].

Three VRS stations were selected at the average distance $1.5 \mathrm{~km}$ from the POKU repeat station and POKU_GOT2 ref- erence mark. The duration of conventional static occupation was determined depending on the baseline vector length according to the rule $20 \mathrm{~min}+2 \mathrm{~min} / \mathrm{km}$ [Hoffmann-Wellenhof et al. 2008]. Considering the baseline vector length of approximately $1.5 \mathrm{~km}$, the duration of occupation was 23 minutes. The survey with one GNSS receiver Trimble R8 took place on April 16, 2011 (Figure 1, right). According to the Rules on the fundamental geodetic works performance (http: / / www.dgu.hr/ UserDocsImages/Pravilnik_o_nacinu_izvodjenja_osnovnih _geodetskih_radova.pdf) the GNSS survey of the $3^{\text {rd }}$ order network has to be performed with: 5 second observation interval, elevation mask $10^{\circ}$, the network adjustment with at least three reference (known) stations. The baseline vectors processing and network adjustment was carried out in Trimble Business Center (TBC) software, ver. 2.20. For baseline vectors processing the GPS and GLONASS data were used along with the broadcast ephemeris. The baselines were processed with precise ephemeris too, but due to short baselines the difference between solutions was negligible and consequently the solution with broadcast ephemeris was retained. The network was adjusted with precision confidence level $95 \%$ and three reference stations with fixed coordinates. The network configuration with fixed and newly determined coordinates along with error ellipses (graphical representation of the magnitude and direction of the error) is shown in Figure 1 (left).

The adjusted ellipsoidal (GRS80) coordinates with their precision (confidence level 95\%) determined with GPPS service of the CROPOS system are given in Table 3. 
The ellipsoidal azimuth computed from coordinates in Table 3 is referred to the azimuth of the direct normal section from the repeat station POKU_SV to the reference mark POKU_GOT2:

$$
\alpha_{n}(\mathrm{GPPS})=359^{\circ} 42^{\prime} 04.7^{\prime \prime} .
$$

Reducing the precision of the coordinates in Table 3 to the confidence level $68 \%(1.00 \sigma)$ and taking into consideration the worst case where the longitudes on both stations are burdened with maximal easting errors in opposite directions, the difference in azimuth is estimated to 1.6". In this case, where the line of sight is oriented in N-S direction, mostly easting $(\mathrm{E}-\mathrm{W})$ errors have influence on the error in azimuth. In the general case, the influence of coordinate errors on both stations on the error in azimuth should be analyzed by taking into account the coordinate errors perpendicular to the line of sight between stations. The coordinate errors perpendicular to the line of sight can be estimated from the error ellipses on both stations. The difference between the direct normal section and geodesic is calculated according to expression:

$$
\alpha_{g}-\alpha_{n}=-\frac{e^{2}}{12 a^{2}} \cos ^{2} \varphi \cdot \sin 2 \alpha_{n} \cdot S^{2}
$$

where $\alpha_{g}$ is the azimuth of the geodesic, $\alpha_{n}$ azimuth of the direct normal section, $e$ is the eccentricity, $a$ is the ellipsoidal semimajor axis, $S$ is the length of the geodesic [Torge 2001]. For the repeat station POKU_SV and parameters of the GRS80 ellipsoid the difference $\left(\alpha_{g}-\alpha_{n}\right)=5 \cdot 10^{-9} "$.

\subsubsection{The application of VPPS service in azimuth determination}

With VPPS service the coordinates were obtained in real time during the survey. According to the Rules on the funda- mental geodetic works performance (http: / / www.dgu.hr/User DocsImages / Pravilnik_o_nacinu_izvodjenja_osnovnih_ geodetskih_radova.pdf), the stations of the supplemental GNSS network (reference network of $3^{\text {rd }}$ order) have to be observed in two independent repetitions (one repetition with three consecutive coordinate determinations, each one with 30 second duration after the successful ambiguity initialization). The second repetition has to be observed two hours after the first one with elevation mask $15^{\circ}$ in both repetitions. The coordinates were determined from altogether six repetitions, the average ellipsoidal coordinates along with standard deviations are given in Table 4.

The azimuth computed from the coordinates in Table 4 was:

$$
\alpha_{n}(V P P S)=359^{\circ} 42^{\prime} 03.3^{\prime \prime} .
$$

Since the station coordinates were determined six times, the computation of 36 azimuth values was enabled. The average azimuth value along with maximal and minimal values as well as the scatter defined as Scatter = Max [ABS(Ave-Min), ABS(Ave-Max)] are given in Table 5.

The comparison of the azimuth values computed from coordinates determined by GPPS service with those determined by VPPS service has given a difference $\alpha_{n}$ (GPPS) $\alpha_{n}(V P P S)=1.4 "$. After the coordinates transformation in CSRS using the transformation parameters valid for the territory of the Zagreb County, the Transverse Mercator plane coordinates were computed along with grid azimuth, convergence of meridian and ellipsoidal azimuth referred to ellipsoid Bessel-1841.

The comparison of the coordinates from Table 1 and Table 6 has led to the coordinate difference $\Delta y=0.022 \mathrm{~m}$ and $\Delta x=0.021 \mathrm{~m}$ for the station POKU_SV, and $\Delta y=0.009 \mathrm{~m}$

\begin{tabular}{ccccc}
\hline Station & Latitude (DMS) & St. Dev. (m) & Longitude (DMS) & St. Dev. (m) \\
POKU_SV & $45^{\circ} 28^{\prime} 22.91643^{\prime \prime}$ & 0.007 & $15^{\circ} 58^{\prime} 42.66675^{\prime \prime}$ & 0.005 \\
POKU_GOT2 & $45^{\circ} 28^{\prime} 41.78176^{\prime \prime}$ & 0.015 & $15^{\circ} 58^{\prime} 42.52677^{\prime \prime}$ & 0.007 \\
\hline
\end{tabular}

Table 4. Ellipsoidal coordinates and their precision (VPPS).

\begin{tabular}{ccccc}
\hline Azimuth (DMS) & Stdev (") & Max (DMS) & Min (DMS) & Scatter (") \\
$359^{\circ} 42^{\prime} 03.3^{\prime \prime}$ & $2.7^{\prime \prime}$ & $359^{\circ} 42^{\prime} 08.1^{\prime \prime}$ & $359^{\circ} 41^{\prime} 58.4^{\prime \prime}$ & $4.9^{\prime \prime}$ \\
\hline
\end{tabular}

Table 5. Azimuth average value from 36 solutions (VPPS).

\begin{tabular}{cccccc}
\hline Station & $\mathbf{y}(\mathbf{m})$ & $\mathbf{x}(\mathbf{m})$ & Grid azimuth (DMS) & $\begin{array}{c}\text { Convergence of } \\
\text { meridian }(\text { DMS })\end{array}$ & $\begin{array}{c}\text { Ellipsoidal azimuth } \\
(\text { DMS })\end{array}$ \\
POKU_SV & 5576879.570 & 5036993.929 & $359^{\circ} 00^{\prime} 07.2^{\prime \prime}$ & $0^{\circ} 42^{\prime} 04.5^{\prime \prime}$ & $359^{\circ} 42^{\prime} 11.7^{\prime \prime}$ \\
POKU_GOT2 & 5576869.426 & 5037576.250 & & \\
\hline
\end{tabular}

Table 6. Transverse Mercator plane coordinates computed from VPPS. 
and $\Delta x=0.041 \mathrm{~m}$ for the station POKU_GOT2 as well as the difference in azimuth $\Delta \alpha_{n}=4.0 "$. These differences are likely to be a consequence of the differences within the positioning methods performed in 2004 and 2011.

The ellipsoidal coordinates from Table 3 (GPPS) were transformed into CSRS using transformation parameters valid for the territory of the Zagreb County. The azimuth computed from transformed coordinates was $\alpha_{n}(C S R S)=359^{\circ} 42^{\prime} 12.5^{\prime \prime}$, compared to the azimuth $\alpha_{n}(G P P S)=359^{\circ} 42^{\prime} 04.7^{\prime \prime}$ gave the azimuth difference $\alpha_{n}(C S R S)-\alpha_{n}(G P P S)=7.8^{\prime \prime}$. It can be inferred that the transformation of coordinates from ETRF2000 reference frame to the CSRS in the area surrounding POKU_SV repeat station has led to such a difference in azimuth values. Considering such a difference of azimuth values, it is recommended to adopt the azimuth and thus the geomagnetic declination in the global reference frame (ETRF2000).

2.3. The dependence of the distance between stations and the accuracy of the azimuth

The comparison of the azimuth values computed from GPPS (which was considered 'absolutely' accurate within this analysis) and VPPS service yielded the difference of 1.4" at the distance between stations of $582.42 \mathrm{~m}$. For the sake of further analysis, the difference in the azimuth values was rounded to 2" (conservative approach) because of the resolution of the circle readings in one-second theodolites (e.g. Zeiss Theo 010B) widely used for geomagnetic surveys. If we assume the homogeneous positional accuracy along the line of sight between the station and the reference mark, the difference in azimuth values depending on the distance is presented in Table 7. From the analysis of the values in Table 7 , it can be concluded that at distances between stations less than $200 \mathrm{~m}$, the assumed homogeneous positional accuracy causes the difference in azimuth greater than 6".

This value should be considered as a threshold in the consideration of the minimal distance between stations because in one-minute optical theodolites the readings of the circles are estimated to $0.1^{\prime}=6^{\prime \prime}$. Therefore, it is confirmed to choose the reference mark at least $200 \mathrm{~m}$ away from the repeat station, like it was recommended earlier already [Newitt et al. 1996]. On the other hand, reference marks that are too far away (several $\mathrm{km}$ ) may be difficult to sight in hot conditions due to atmospheric refraction or in hazy and misty conditions [Newitt et al. 1996].

At short distances special attention should be paid to the setup (centering and levelling) of the mark (label) over the reference mark as well as the theodolite over the repeat station. The azimuth error of $1 "$ at a distance of $200 \mathrm{~m}$ causes the arc length of $1 \mathrm{~mm}$, similarly at a distance of $500 \mathrm{~m}$ the arc length rises to $5 \mathrm{~mm}$.

The reference mark sighting is usually performed in two theodolite faces due to the elimination of some instrumen-

\begin{tabular}{cc}
\hline Distance between stations $(\mathbf{m})$ & $\Delta \boldsymbol{\alpha}(")$ \\
1000 & 1.2 \\
600 & 1.9 \\
500 & 2.3 \\
400 & 2.9 \\
300 & 3.9 \\
250 & 4.7 \\
200 & 5.8 \\
150 & 7.8 \\
100 & 11.7 \\
\hline
\end{tabular}

Table 7. Dependence of the azimuth accuracy and the distance between stations.

tal errors. For example, the average reading from sighting the reference mark with the optical theodolite (with two diametrically opposite readings) is free from the collimation error, the error of the horizontal axis, and eccentricity of the alidade [Macarol 1978].

Special attention should be paid to the levelling of the theodolite because the influence of the error of the vertical axis on the horizontal circle readings cannot be eliminated by taking the average of readings in both theodolite faces [Benčić 1990]. This is especially true for a steep line of sight. The error of the horizontal direction due to the error of the vertical axis is given by the expression [Benčić 1990]:

$$
(v)=v \cdot \sin \alpha \cdot \operatorname{ctg} z
$$

where $v$ is the angle between the vertical axis of the theodolite and the plumb line, $\alpha$ is the angle in horizontal circle plane between the line of sight and the intersection of the plane of the horizontal circle and the true horizontal plane, $z$ is the zenith distance of the line of sight. According to the expression (2), the horizontal direction error due to the error of the vertical axis is minimized for zenith distance readings $z \approx 90^{\circ}$. This is the reason why the reference mark should be chosen on the horizon around the repeat station.

\section{Astronomic azimuth determination methods}

The astronomic azimuth is determined by means of the two most popular methods [Terzić 1988]:

- Hour-angle method,

- Zenith-distance method.

By hour-angle method the azimuth is calculated from the known astronomic latitude $\Phi$ of the station, known declination $\delta$ as well as the hour angle $t$ of the observed celestial body. By zenith-distance method the azimuth is calculated from know astronomic latitude $\Phi$ of the station, known declination $\delta$ as well as the zenith distance $z$ of the observed celestial body (Figure 4, left). 


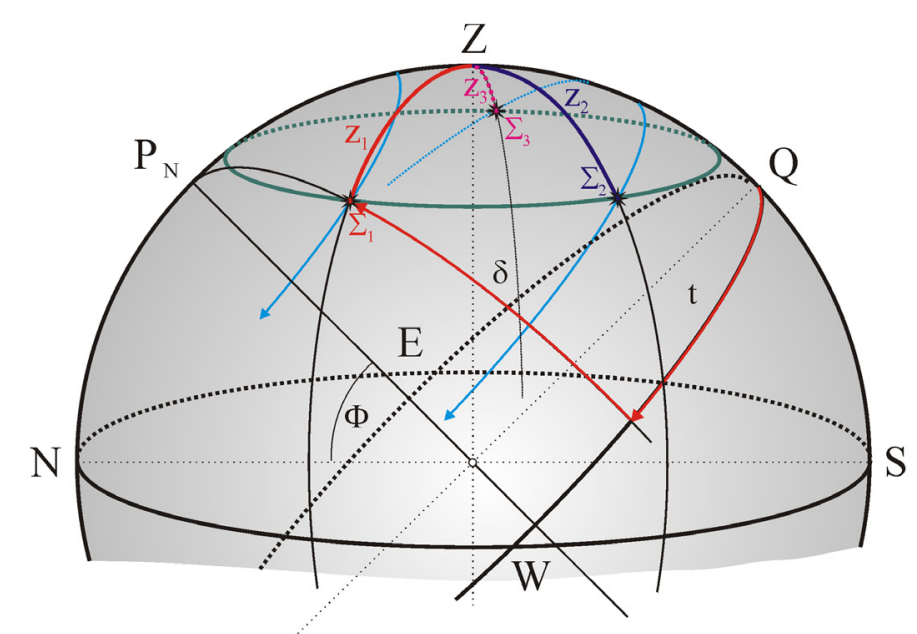

Figure 2 (above). The problem of three heights. Figure 3 (right). Automated system for the simultaneous $(\Phi, \Lambda)$ determination.

Obviously, in both methods the astronomic latitude $\Phi$ have to be known, hence in the sequel the astronomic coordinate determination will be considered.

\subsection{Simultaneous determination of the astronomic coordinates}

In the theory of astrometry there are methods for individual as well as for simultaneous determination of the astronomic station coordinates (latitude $\Phi$, longitude $\Lambda$ ), but in astrogeodetic practice mostly simultaneous methods are used. Simultaneous determination of the coordinates from the measurements of the time needed for the stars to pass through the same almucantar by means of astrolabe with compensator meets a few basic conditions: accuracy, light (portable) observation equipment and significantly shorter observation period [Špoljarić and Solarić 2010].

The determination of zenith distances of the celestial body is burdened with instrumental errors as well as refraction influence. In the 1808 C.F. Gauss suggested to use the time needed for the three stars to pass through the same almucantar (known in the literature as the problem of three heights) instead of measuring the zenith distance for the simultaneous determination of the astronomic coordinates of the station.

From the sphere triangle (Figure 2, Figure 4-right) celestial pole $(\mathrm{P})$ - zenith $(\mathrm{Z})$ - celestial body $\left(\Sigma_{1}\right)$, with known apparent coordinates of the stars $\Sigma_{i}$ (right ascension $\alpha_{i}$, declination $\delta_{i}$ ) and sideral time of the star's upper transit at Greenwich meridian GAST $_{i}$ (Greenwich Apparent Sideral Time), the zenith distance of the celestial body is obtained

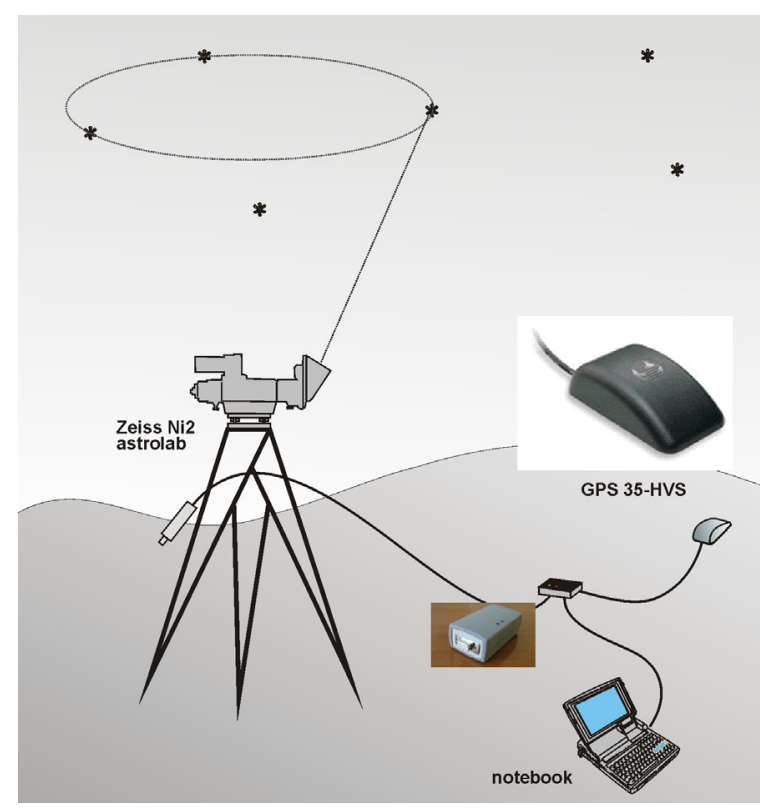

according to expression [Schödlbauer 2000]:

$$
\cos z=\sin \Phi \sin \delta_{i}+\cos \Phi \cos \delta_{i} \cos t_{i}
$$

There, $t_{i}=\mathrm{GAST}_{i}+\Lambda-\alpha_{i}$ is the hour-angle of the celestial body. In practice, usually twenty or more stars evenly distributed over the almucantar of constant zenith distance $z$ are observed. The observation of additional stars (more than three) yields to redundant measurements so the unknowns are determined through the least-squares adjustment procedure.

The automated measurement system for simultaneous determination of the astronomic coordinates of the station consists of an astrolabe Zeiss Ni2, Garmin GPS 35 HVS receiver for accurate time signals and notebook computer with software for the processing of the measurements (Figure 3). With this system the clock correction determination has been eliminated, the selection of the stars to be observed is done on the computer screen, the measurements are shorter and could be processed directly on the field [Špoljarić and Solarić 2010].

The astronomic coordinates of the repeat station POKU_SV were determined upon the observations performed on the evening of 5 May 2011. Altogether 25 stars were observed, but after the astronomic coordinates calculation by least-squares adjustment, one observation was rejected due to significantly higher residuals. The final solution was calculated with 24 stars, the astronomic coordinates with their precision are given in Table 8.

\begin{tabular}{ccc}
\hline Astronomic coordinates & $($ DMS $)$ & Standard deviation (") \\
$\Phi$ & $45^{\circ} 28^{\prime} 23.8^{\prime \prime}$ & $\pm 0.7^{\prime \prime}$ \\
$\Lambda$ & $15^{\circ} 58^{\prime} 41.1 " 1 "$ & $\pm 0.5^{\prime \prime}$ \\
\hline
\end{tabular}

Table 8. Astronomic coordinates of the POKU_SV repeat station. 

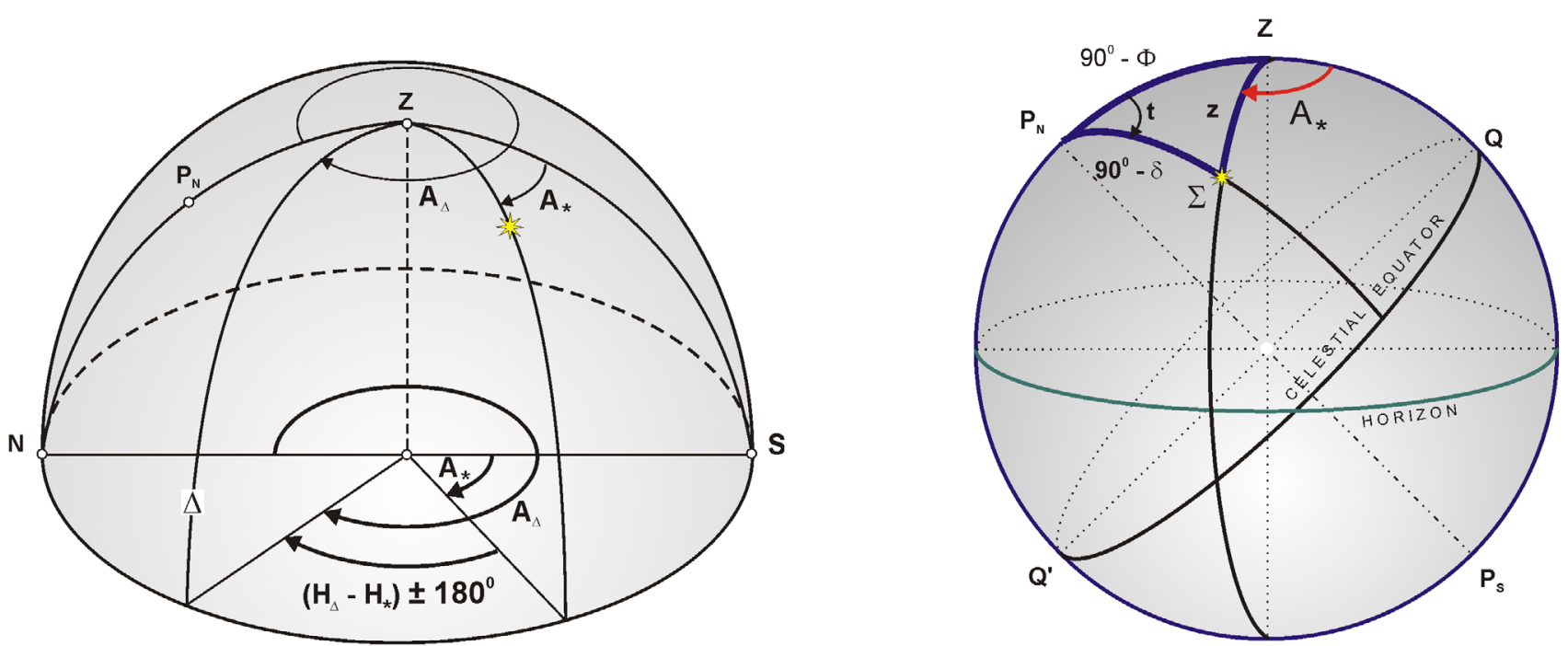

Figure 4. Relationship between the astronomic azimuth of the celestial body and the reference mark (left). Astronomic azimuth on the celestial sphere (right).

\subsection{The hour-angle method}

The astronomic azimuth $A_{\Delta}$ of the reference mark on the surface of the Earth is determined from the azimuth $A *$ of the celestial body (star or a Sun) at the moment of observation and the measurement of the horizontal angle between the reference mark and the celestial body (Figure 4, left).

The azimuth of the celestial body $\mathrm{A}^{*}$ can be computed from the known hour angle $t$ and declination $\delta$ of the celestial body, and astronomic latitude $\Phi$ of the station according to the expression [Schödlbauer 2000]:

$$
\operatorname{tg} A_{*}=\frac{\sin t}{\sin \Phi \cos t-\cos \Phi \operatorname{tg} \delta} .
$$

Differencing the expression (4) by the variables $\mathrm{A}^{*}, \Phi, t$ and $\delta$ and after some rearrangement the next expression is obtained ( $q$ is the angle between the hour circle and the vertical circle of the observed celestial body) [Terzić 1988]:

$$
\Delta A_{*}=\frac{\sin q}{\sin z} \Delta \delta-\sin A_{*} \cdot \operatorname{ctg} z \cdot \Delta \Phi+\frac{\cos \delta \cdot \cos q}{\sin z} \Delta t .
$$

Upon analysis of the expression (5) can be inferred that: - the error of the astronomic latitude $\Delta \Phi$ has no impact on the precision of the azimuth if

- the celestial body was observed in the vicinity of the meridian where $A^{*} \approx 180^{\circ}$,

- the error of the hour angle $\Delta t$ has no impact on the precision of the azimuth if the celestial body was observed in the vicinity of the celestial pole where $\delta \approx 90^{\circ}$,

- the error of the hour angle $\Delta t$ has no impact on the precision of the azimuth if the celestial body was observed in the maximal elongation $\left(q=90^{\circ}\right.$ or $\left.q=270^{\circ}\right)$.

All these conditions are best fulfilled for the observation of the star Polaris ( $\alpha$ Ursae Minoris). If the clock correction was well determined i.e. $\Delta t$ was a small value, the astronomic azimuth can be well determined from the observation of the Sun close to the sunrise or the sunset where $z \approx 90^{\circ}$. If the Sun was observed symmetrically to the local meridian during the morning and evening sets, the errors $\Delta \Phi$ and $\Delta \delta$ canceled out.

\subsubsection{Determination of the astronomic azimuth on the POKU} repeat station

The observations for the determination of the astronomic azimuth on the POKU_SV repeat station were carried out in the evening on 26 May 2011. The astronomic azimuth was determined by the hour-angle method and observations to the reference mark POKU_GOT2 and Polaris which is a bright star with apparent magnitude 2.02. Polaris can be sighted starting from 3 hours before the sunset and ending at 3 hours after the sunrise.

The automated measurement system for the determination of the astronomic azimuth consists of: electronic theodolite Kern E2, notebook computer for the registration of the horizontal directions and zenith distances to the reference mark and celestial body as well as for the recording of the time of star observation (Figure 5, left). The electronic theodolite Kern E2 has the resolution of the horizontal and vertical circle readings of 0.1 mgon (0.324") and the dual-axis compensator with \pm 0.1 mgon accuracy and \pm 50 mgon of operating range [Benčić 1990]. The reference mark was labeled with an illuminated signal customized for the sighting in the darkness (Figure 5, right). The observations were carried out in both theodolite faces. The compensator (automatic vertical index) was turned on for the readings of the horizontal and vertical circles, so the observed horizontal directions and zenith distances were almost free from the nonverticality error of the instrumental vertical axis.

Due to some problems concerning the ephemeris computation within the automated system, the time and theodolite circles reading were recorded by the software, but the further azimuth calculations were carried out in the office 

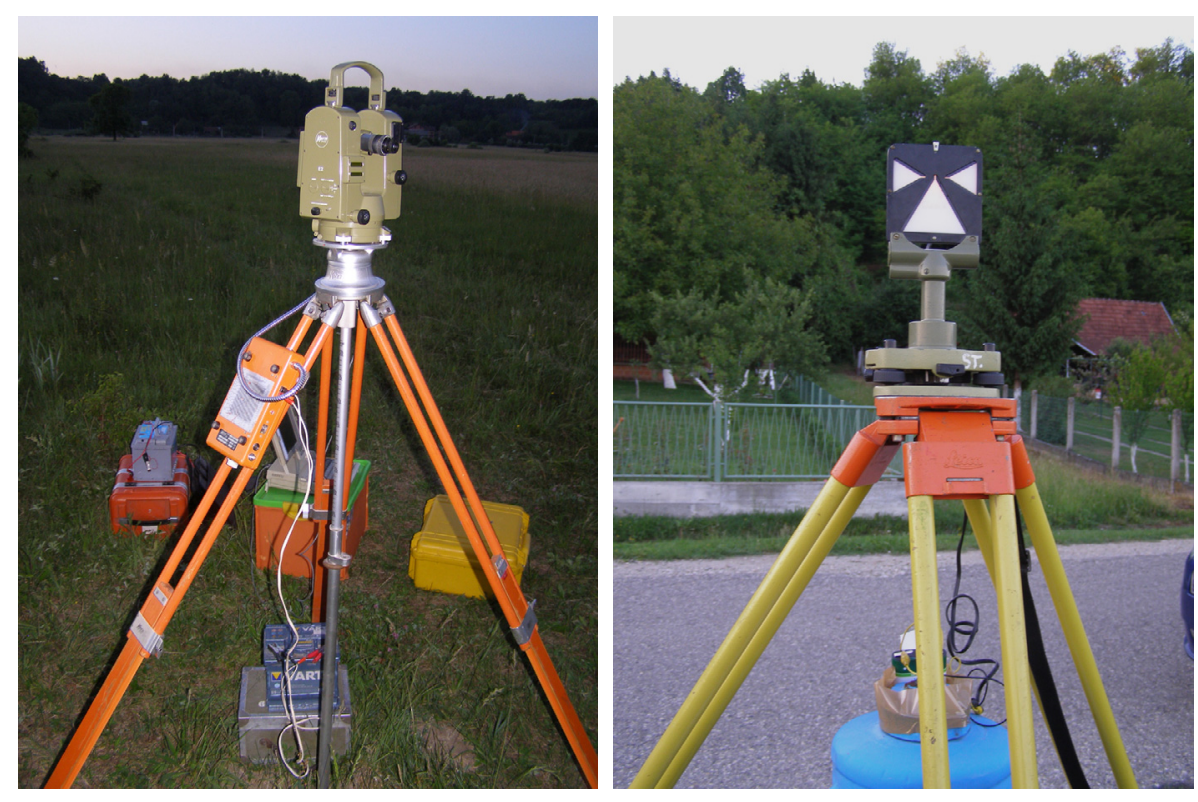

Figure 5. Automated measurement system (Kern E2 + notebook computer) (left). Illuminated signal on the reference mark for the observation in the darkness (right).

according to the procedure described in sequel.

From the known astronomic latitude $\Phi$, measured horizontal angle between the reference mark $\Delta$ and the star * (Polaris) with apparent coordinates $(\alpha, \delta)$ and known the time of observation $T$, the instantaneous hour angle of the observed star was obtained from the expression [Špoljarić 2010]:

$$
\begin{gathered}
t=L A S T-\alpha \\
L A S T=\left[T+c_{Z T}-\Delta_{Z T}+(U T 1-U T C)\right] \\
\cdot 1.002737909+S_{0}+\Lambda
\end{gathered}
$$

where $T$ is the time reading of the clock synchronized to $Z T=$ CET $\left(\right.$ Zonal Time $=$ Central European Time), $c_{Z T}$ is the difference between ZT and UTC (during the summertime CET $\left.-\mathrm{UTC}=2^{\mathrm{h}}\right), \Delta_{Z T}$ is the clock correction to the zonal time, (UT1-UTC) is the difference taken from IERS BULLETIN-A at http:/ / maia.usno.navy.mil/ser7/ser7.dat, coefficient 1.002737909 is used for the conversion of the mean Sun time to mean sideral time, $S_{0}$ is the sideral time at $0^{\mathrm{h}} \mathrm{UT}$ at Greenwich meridian $\left(S_{0}=\right.$ GAST) obtained from Astronomisches Rechen - Institut, Database for the Apparent Places of Fundamental Stars at http: / / www.ari.uni-heidelberg. de/datenbanken/ariapfs/query.html.

Once the instantaneous hour angle $t$ of the star has been determined, the astronomic azimuth of the star is calculated by expression (4). Astronomic coordinates $(\alpha, \delta)$ of Polaris were downloaded from the same Web site of the Astronomisches Rechen - Institut. The coordinates are based on the FK6 (Fundamental Catalog), and are given for every day at the time of upper transit at the Greenwich meridian as well as at $0^{\mathrm{h}} \mathrm{UT}$. The apparent coordinates of the star were given considering the precession-nutation model IAU 20002006, including POP3 precession theory (http://www.ari. uni-heidelberg.de/datenbanken/ariapfs/intro.html).

For the astronomic azimuth calculation (4), the apparent coordinates were interpolated for the time of observation by means of the Bessel interpolation function. The calculated astronomic azimuth of the star was corrected for the daily aberration according to

$$
\Delta A=-0.32^{\prime \prime} \cos \Phi \cos A \operatorname{cosec} z .
$$

During the observation of Polaris, its azimuth was $A \approx$ $180^{\circ} \pm 1^{\circ}$ (calculation based on astronomic latitude of the POKU station as well as on the star declination $\delta$ for the day of observation) i.e. $\cos A \approx-1$, taking into account that for Polaris was $z \approx \delta-\Phi$ then the correction for the daily aberration was $\Delta A=+0.32 "$.

The astronomic azimuth is reckoned clockwise from the south point $S$ of the horizon (Figure 4, left). In order to obtain the azimuth reckoned from the north point $\mathrm{N}$ of the horizon $\pm 180^{\circ}$ has to be added to the astronomic azimuth $A^{*}$.

From the astronomic azimuth of the star $\mathrm{A}^{*}$, the astronomic azimuth of the reference mark is calculated by expression where $H \Delta$ and $H^{*}$ are the horizontal directions to the reference mark and the observed star respectively:

$$
A_{\Delta}=A^{*}+\left(H_{\Delta}-H^{*}\right) \pm 180^{\circ}
$$

The final solution of the astronomic azimuth was calculated from 8 sets with average value $A=359^{\circ} 42^{\prime} 04.4^{\prime \prime}$ and standard deviation $\pm 2.6^{\prime \prime}$.

\subsection{The zenith-distance method}

The azimuth of the celestial body $A^{*}$ can be computed from the known zenith distance $z$ and declination $\delta$ of the celestial body and astronomic latitude $\Phi$ of the station ac- 
cording to the expression [Terzić 1988]:

$$
\cos A_{*}=-\frac{\sin \delta-\sin \Phi \cdot \cos z}{\cos \Phi \cdot \sin z} .
$$

Differencing the expression (10) by the variables $A^{*}, \Phi$, $z$ and $\delta$ and after some rearrangement the next expression is obtained ( $q$ is the angle between the hour circle and the vertical circle of the observed celestial body) [Terzić 1988]:

$$
\Delta A_{*}=\frac{\cos q}{\cos \Phi \cdot \sin t} \Delta z-\frac{\operatorname{ctg} t}{\cos \Phi} \Delta \Phi+\frac{\Delta \delta}{\cos \Phi \cdot \sin t} .
$$

Upon analysis of the expression (11) can be inferred that: - if the celestial body was observed in the vicinity of the meridian, the influence of the errors $\Delta z, \Delta \Phi$ and $\Delta \delta$ to the error in azimuth become too high,

- if the celestial body was observed in the maximal elongation $\left(q=90^{\circ}\right.$ or $\left.q=270^{\circ}\right)$, the error $\Delta z$ has no influence on the azimuth precision,

- if the celestial body was observed when $t=90^{\circ}$ or $t=$ $270^{\circ}$ the latitude error $\Delta \Phi$ has no effect on the azimuth precision.

At mid-latitudes, by the zenith-distance method good precision can be obtained if Polaris was observed in the maximal elongations. The astronomic azimuth determination by the hour-angle method provides high precision at all the times, hence zenith-angle method has no practical importance. During the observations by the zenith-distance method the time readings are rounded to one minute, because the time readings are needed only for the interpolation of the star coordinates.

The apparent zenith angle $z^{\prime}$ observed with theodolite must be corrected for refraction $R$ in order to get the true zenith angle of the celestial body [Terzić 1990]:

$$
z=z^{\prime}+R \text {. }
$$

According to Laplace's theory of refraction, at the temperature $10{ }^{\circ} \mathrm{C}$ and air pressure $1013.25 \mathrm{mbar}$, the refraction for the celestial body at the zenith distance $0^{\circ}-79^{\circ}$ is calcu- lated by expression [Terzić 1990]:

$R=58.12^{\prime \prime} \operatorname{tg} z^{\prime}-0.067^{\prime \prime} \operatorname{tg}^{3} z^{\prime}+0.0002 \operatorname{tg}^{5} z^{\prime}-0.000001 \operatorname{tg}^{7} z^{\prime}$

The advantage of an astronomic azimuth determination by observation of the Sun is that the measurements are performed during the day. The drawback is in the lower precision. The astronomic azimuth determination by the zenith-distance method provides lower precision due to simultaneous registration of the horizontal and vertical readings as well as possible errors in refraction at certain zenith angles [Terzić 1988].

The influence of the daily aberration on azimuth determination by observation of the Polaris is practically the same (independently on the chosen azimuth determination method). Usually, the Sun is observed in prime vertical where, according to (11), $\Delta A=0$.

\subsection{Comparison of the hour-angle and zenith-distance method}

The automated measurement system for determination of the astronomic azimuth was tested by observing the Sun using the zenith-distance as well as hour-angle method [Solarić and Špoljarić 1988]. Using the zenith-distance method the Sun was observed almost during whole day (except the short period around the local noon) in 219 observation sets. The analysis of the azimuth results has shown that the optimal observation periods for azimuth determination were in the morning (7 till 9) and afternoon (15 till 17), but not around the local noon (Figure 6, left).

Furthermore, it was found out that the observations within the optimal period should not be done in more than 5 to 7 sets because the observations from additional sets haven't led to the improvement of the accuracy. The mean value of the azimuth was obtained with standard deviation of 2.6" [Solarić and Špoljarić 1988].

Using the hour-angle method, the Sun was observed in 198 sets during the whole day (without the pause at the noon). The analysis of the measurements has indicated that this method should be used during whole the day but the best pre-
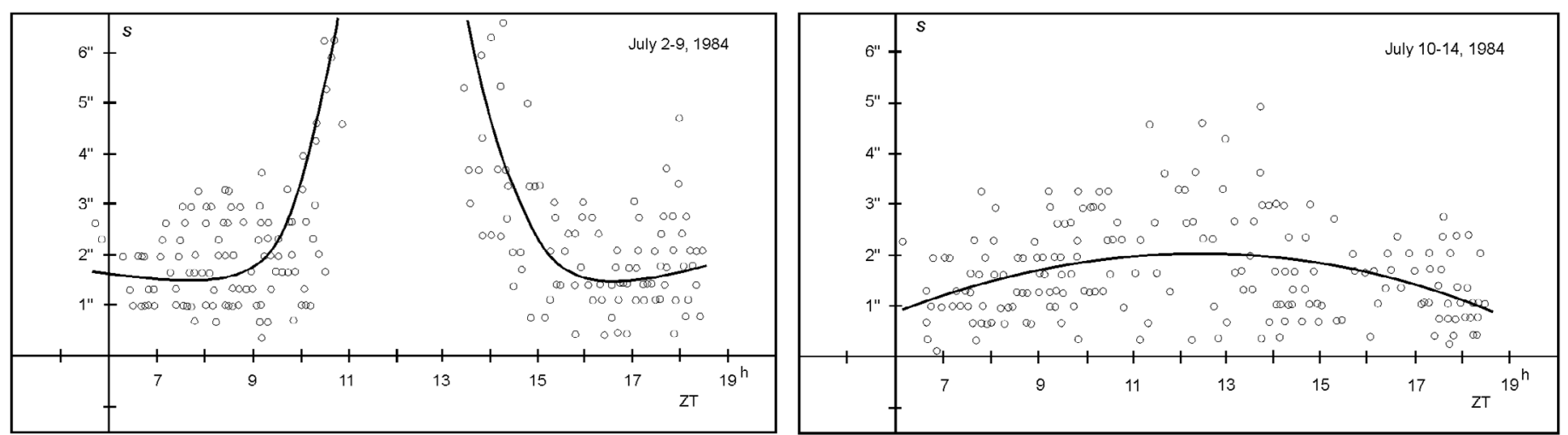

Figure 6. Daily changes of the standard deviations from individual sets of the Sun observations using the zenith-distance (left) and hour-angle method (right). (LTST = Local True Solar Time) [Solarić and Špoljarić 1988]. 
cision is obtained in the morning and afternoon (Figure 6, right). It was concluded that the azimuth should not be observed in more than 3 to 5 sets during the optimum period. Similarly, as stated for the zenith-distance method, the increasing of the number of sets has not led to the improvement of the accuracy. The mean value of the azimuth was obtained with standard deviation of 1.9" [Solarić and Špoljarić 1988].

The zenith-distance method of the astronomic azimuth determination by observing the stars was tested too [Solarić et al. 1990]. Four stars were observed in the vicinity of the digression (maximal elongation), in the prime vertical and significantly apart from the prime vertical. During ten nights 347 sets were observed. The analysis of the measurements has indicated that no more than 7 sets should be observed using this method. The average standard deviation of the azimuth determination (from 6 sets) from the observation of the star in digression was 1.4", and from the star in the prime vertical was $1.9^{\prime \prime}$.

The azimuth was determined from the observation of Polaris by the hour-angle method too [Solarić and Špoljarić 1992]. The observations were performed simultaneously by two observers and two theodolites Kern E2 in the series of 10 sets. Altogether 41 series i.e. 460 sets were observed during seven nights. Using all sets observed in a single evening, the standard deviation was $0.88^{\prime \prime}$. The average standard deviation in all series (seven-day period) was $0.5 "$ (Figure 7, left). The analysis of the results has indicated that the azimuth should not be observed in more than 5 sets because the further increase of the number of sets $n$ does not significantly change the standard deviation amount (Figure 7, right).

\subsection{Reduction to the ellipsoid}

The azimuth $A$ determined by astronomic observation is referred to the plumb line, in order to obtain the azimuth $\alpha_{n}$ which is referred to the ellipsoid normal, the effect of the deflection of the vertical has to be taken into account according to Laplace's equation of orientation [Torge 2001]:

$$
\alpha_{n}-A_{\Delta}=-\eta \cdot \tan \varphi+\frac{\eta \cdot \cos \alpha-\xi \cdot \sin \alpha}{\tan \zeta}
$$

where $\zeta$ is the ellipsoidal zenith-distance to the reference mark, $\eta$ and $\xi$ are the components of the deflection of the vertical:

$$
\begin{aligned}
& \xi=\Phi-\varphi \\
& \eta=(\Lambda-\lambda) \cdot \cos \varphi
\end{aligned}
$$

From the astronomic coordinates $(\Phi, \Lambda)$ (Table 8 ) and the ellipsoidal coordinates $(\varphi, \lambda)$ (Table 3$)$ of the station POKU_SV, the components of the deflection of the vertical were computed according to the equation (15): $\xi=0.9^{\prime \prime}, \eta=-1.1$ ".

The astronomic latitude, deflection of the vertical and zenith distance to the reference mark ( $\left.\zeta \approx z=89^{\circ} 53^{\prime} 23.7^{\prime \prime}\right)$ yielded the difference $\left(\alpha_{n}-A_{\Delta}\right)=1.1 "$. The astronomic azimuth reduced to the ellipsoid according to (14) was:

$$
\alpha_{n}(A S T R O)=359^{\circ} 42^{\prime} 05.5^{\prime \prime}
$$

and compared to the ellipsoidal (geodetic) azimuth obtained from GPPS service yielded the difference $\Delta \alpha_{n}=\alpha_{n}($ ASTRO) $\alpha_{n}(G P P S)=+0.8 "$. This difference was expected since the standard deviation of the astronomic azimuth was $\pm 2.6 "$, proving that both azimuth determination methods have led to correct results.

The gyro-theodolites have been developed for the determination of the astronomic azimuth [Torge 2001]. In order to reduce the astronomic azimuth to the ellipsoid, the components of the deflection of the vertical have to be known.

\section{Some practical aspects of the azimuth determinations}

As shown in previous chapters, the azimuth from the repeat station POKU_SV toward the reference mark POKU_GOT2 was determined with three independent methods: GPPS and VPPS services of the CROPOS system as well as with the hour-angle method observing the star Polaris. Within the VPPS service, the coordinates of the repeat station as well as the coordinates of the reference mark were determined with one Trimble R8 GNNS receiver enabled to receive the network RTK corrections from CROPOS system via a wireless Internet. The plane coordinates were obtained
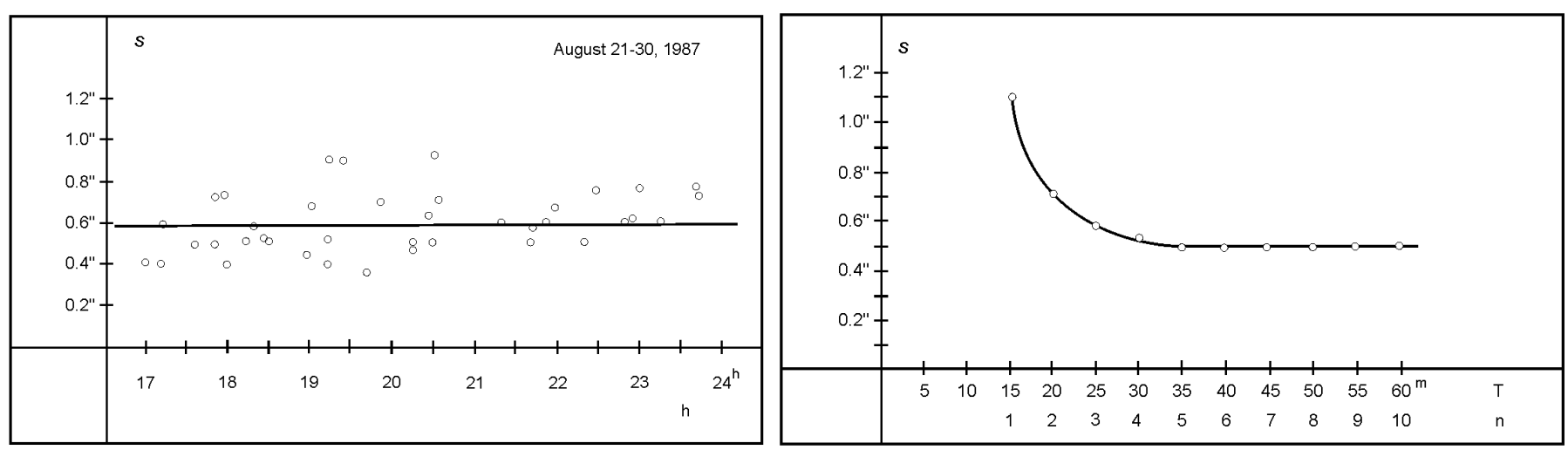

Figure 7. Average standard deviation in all series, on the horizontal axis $\mathrm{h}$ is the hour angle of Polaris (left), Dependence of the average standard deviation on the number of sets $n$ and time needed for the observations T (right) [Solarić and Špoljarić 1992]. 
in real time during the survey with standard deviation within $2 \mathrm{~cm}$ which is consistent with the specifications given in Table 2. For the coordinates determination with conventional RTK method, at least two GNSS receivers are required (base and rover), one observing at the station with known coordinates (reference receiver) and broadcasting the corrections through the radio link or a cellular network to the rover receiver. The coordinates of the rover receiver station are determined from the satellite observations and the received corrections. The drawback of the conventional RTK method is the need for an additional GNSS receiver (reference receiver) as well as the dependence of the accuracy of the rover station coordinates on the distance to the reference receiver [Premužić et al. 2010].

For the coordinate determination with GPPS service of the CROPOS system, just one GNSS receiver is needed taking observations on the repeat station and reference mark. The station occupation is determined depending on the baseline vectors length to the selected VRS points with known coordinates. For the conventional static relative method (particularly for baselines up to some $20 \mathrm{~km}$ ), the station occupation for dual frequency (L1+L2) observations is determined according to the rule: $20 \mathrm{~min}+2 \mathrm{~min} / \mathrm{km}$ of the baseline vector length. These values are based on the visibility of four satellites, good geometry and normal atmospheric conditions [Hofmann-Wellenhof et al. 2008]. The plane coordinates of the stations were determined with the accuracy better than $1 \mathrm{~cm}$ (Table 3) which is in accordance with the characteristics of GPPS service (Table 2). If the conventional static relative GNSS method were used for the coordinate determination, then at least two GNSS receivers would be needed, one observing at the unknown station, the other(s) at the station(s) with known coordinates. In that case, of course, the use of an additional or more GNSS receivers would extend the duration of the observation, and thus increase the cost of the entire procedure.

The basic prerequisite for the use of network solutions (e.g. GPPS and VPPS service) is the existence of the CORS network. In many European countries (e.g. Germany, Austria, Switzerland, Hungary, Great Britain etc.) such a network providing similar services is already established. In the countries where the CORS network has not been already established, the coordinates could be determined by the conventional static relative GNSS method or by the conventional RTK method provided that there are stations of the geodetic network. At high geodetic latitudes (polar region), the GNSS methods provide slightly worse results due to satellite constellation.

In order to determine the azimuth by methods of geodetic astronomy, the astronomic station coordinates have to be known. The astronomic coordinates of the repeat station POKU_SV were determined with the automated measurement system which includes the astrolabe Zeiss Ni2, the GPS receiver for the time signals and notebook computer with the appropriate software for measurement processing. For the determination of the astronomic azimuth, the automated measurement system was used which consists of the electronic theodolite Kern E2, notebook computer with the appropriate software and the illuminated signal for the observations in the darkness. The nonmagnetic theodolite Zeiss 010B which is usually used for the declination/inclination observations is not suitable for the astronomic azimuth determinations within the automated system. The hour-angle azimuth determination method by observation of the star Polaris, at the mid-latitudes provides the azimuth with precision better than 1". At high latitudes on the Northern Hemisphere (polar region) the line of sight to the Polaris is steep whereas on the lower latitudes (equatorial regions) its sighting is burdened with the refraction affecting the accuracy of the azimuth determination. Similar circumstances apply to the southern hemisphere where, instead of the Polaris, another star near the southern celestial pole could be observed.

The mass of the Trimble R8 GNSS receiver which was used within the GPPS and VPPS service coordinate determination method (including the carrying case, controller, tribrach and tripod) was estimated to approximately $10 \mathrm{~kg}$. The mass of the automated measurement system for the determination of the astronomic coordinates (including astrolabe Zeiss Ni2, tripod and the notebook computer) was estimated to approximately $7 \mathrm{~kg}$, whereas the mass of the equipment for the astronomic azimuth determination (electronic theodolite Kern E2, tripod and the additional tripod with the illuminated signal) was estimated to $15 \mathrm{~kg}$.

The main characteristics of methods used in the azimuth determination are summarized in Table 9.

\section{Conclusions}

The accuracy of the azimuth determination has direct impact on the accuracy of the geomagnetic declination that follows from its definition as the ellipsoid (geodetic) azimuth of the magnetic meridian. The azimuth determination methods using GPPS and VPPS services of the CROPOS system were tested and compared at the POKU_SV repeat station. The ellipsoidal azimuth calculated from coordinates determined from the static relative GNNS positioning and GPPS service was considered as 'absolutely' accurate and it was compared to the azimuth calculated from the coordinates obtained with the VPPS service. The difference between azimuth obtained from the GPPS and VPPS service was 1.4" at the distance (repeat station - reference mark) of $582.42 \mathrm{~m}$. If the homogenous positioning accuracy was assumed, the reference mark has to be chosen at a minimal distance of 200 $\mathrm{m}$ away from the repeat station as it was already known. At that distance the assumed positioning accuracy led to an azimuth error of 6 " which was considered as the threshold value of the azimuth error. The advantage of azimuth de- 


\begin{tabular}{|c|c|c|c|c|}
\hline Method & GPPS service & VPPS service & $\begin{array}{c}\text { Automated measurement } \\
\text { system }(\Phi, \Lambda)\end{array}$ & $\begin{array}{c}\text { Automated measurement } \\
\text { system }(A)\end{array}$ \\
\hline Coordinate accuracy & $<1 \mathrm{~cm}$ & $<2 \mathrm{~cm}$ & $\begin{array}{l}<1^{\prime \prime}(\Phi) \\
<1^{\prime \prime}(\Lambda)\end{array}$ & ---- \\
\hline Azimuth accuracy & ----- & ----- & ----- & $<1^{\prime \prime}$ \\
\hline Observation duration & $\begin{array}{l}\text { Depending on the } \\
\text { baseline vectors length }\end{array}$ & $\begin{array}{l}2 \times 5 \text { minutes with } \\
2 \text { hours time span }\end{array}$ & 1.5 hours & 45 minutes \\
\hline Post processing/ Real time & Post processing & Real time & Real time & Real time \\
\hline $\begin{array}{l}\text { Target station to be } \\
\text { occupied }\end{array}$ & Yes & Yes & No & No \\
\hline Mass of the equipment & ca. $10 \mathrm{~kg}$ & ca. $10 \mathrm{~kg}$ & ca. $7 \mathrm{~kg}$ & ca. $15 \mathrm{~kg}$ \\
\hline
\end{tabular}

Table 9. Main characteristics of the used azimuth determination methods.

termination with VPPS service was that the coordinates were obtained during the survey, but for the improvement of the coordinate accuracy the observations have to be performed in two independent repetitions, each one with three coordinate determinations. The most reliable coordinates were determined by static relative GNSS observations, but the azimuth computation was done in the post-processing. The ellipsoidal azimuth calculation from coordinates obtained from the GPPS service before transformation (GRS80 ellipsoid) and after transformation (Bessel 1841) gave the azimuth difference of 7.8". That was the proof that the azimuth and thus the geomagnetic declination have to be referred to a global ETRF2000 reference frame of the ETRS89 coordinate system, instead of being referred to a local system. That should be a step toward the unification of declination determination all over the European continent. The azimuth obtained from the GPPS service was compared to the azimuth value computed during the POKU_SV repeat station setup in 2004: the difference of 4.0 " can be attributed to the difference in positioning methods. The astronomic coordinates of the POKU_SV repeat station were simultaneously determined with the automated measuring system. The components of the deflection of the vertical were computed from the ellipsoidal and astronomic coordinates of the station and subsequently used for the reduction of the astronomic to the ellipsoidal azimuth. The astronomic azimuth was determined with hour-angle method observing the star Polaris. The azimuth was calculated as average from 8 sets with standard deviation $2.6 "$. After the reduction to the ellipsoid, the comparison with the azimuth obtained by the GPPS service yielded the difference +0.8 ". Independent azimuth determination methods (GPPS, VPPS, Hour-angle + Polaris) tested on the POKU_SV repeat station yielded the azimuth value with small differences proving that the az- imuth was accurately determined. The comparison of the azimuth determination methods by observing the Sun pointed out that the hour-angle method can be used almost whole the day, but better results were obtained from morning and afternoon optimal periods. Generally, astronomic azimuth determination methods by observing the stars led to better results in comparison to the result yielded by observing the Sun. At mid-latitudes observing the Polaris by hourangle method has shown to be the optimal astronomic azimuth determination method. The accurate time required for the azimuth determination by hour-angle method is achievable today by GPS receivers within the automated measuring system. Considering the required equipment and time needed for the azimuth determination, as well as the achievable accuracy, the VPPS method can be recommended for the determination of the azimuth adhering to the specific observation rules.

Acknowledgements. The GNSS receiver Trimble R8 used for the preparation of this paper was borrowed by the State Geodetic Administration of the Republic of Croatia, Sector for State Survey, Department for Basic Geodetic Works. Thanks to the Astronomisches Rechen-Institut (ARI) of the University of Heidelberg, Germany, for providing the data of the Apparent Places of Fundamental Stars (APFS).

\section{References}

Bašić, T. (2009). Unique transformation model and new geoid model of the Republic of Croatia, Reports on the scholarly projects in the period 2006-2008, State Geodetic Administration of the Republic of Croatia, Zagreb, Croatia, 5-21 (in Croatian).

Benčić, D. (1990). Geodetic instruments, Školska knjiga Zagreb, Croatia (in Croatian).

Brkić, M., D. Šugar, M. Rezo, D. Markovinović and T. Bašić (2006). Croatian Geomagnetic Repeat Station Network, 
"Geomagnetics for Aeronautical Safety: A Case Study in and around the Balkans", NATO Security throug Science Series, Proceedings of the NATO Advanced Research Worksshop on New Data for the Magnetic Field in the former Yugoslav Republic of Macedonia for Enhanced Flying and Airport Safety, Ohrid, 18-22 May 2005, Springer, Dordrecht, The Neatherlands, 137-143.

Hofmann-Wellenhof, B., H. Lichtenegger and E. Wasle (2008). GNSS - Global Navigation Satellite Systems, Springer-Verlag, Wien/New York.

Jankowski, J., and C. Sucksdorff (1996). Guide for magnetic measurements and observatory practice, IAGA, Boulder, USA, 15.

Macarol, S. (1978). Practical geodesy, Tehnička knjiga, Zagreb, Croatia (in Croatian).

Marjanović, M. (2010). CROPOS - Croatian Positioning System, Ekscentar, Student journal of the Faculty of Geodesy, Student organization, Faculty of Geodesy, Zagreb, Croatia, 28-34 (in Croatian).

Newitt, L.R., C.E. Barton and J. Bitterly (1996). Guide for Magnetic Repeat Station Surveys, IAGA, Buolder, USA, 22.

Premužić, M., D. Šugar and M. Marjanović (2010). Concepts of network RTK solutions, Proceeding of the III Symposium of the chartered geodetic engineers, Croatian Chamber of Chartered Geodetic Engineers, Opatija, 2223 October 2010, Croatia, 174-186 (in Croatian).

Schödlbauer, A. (2000). Geodetic Astronomy, Walter de Gruyter Berlin, New York, USA (in German).

Solarić, N., and D. Špoljarić (1988). Accuracy of the Automatic Grid Azimuth Determination by Observing the Sun Using Kern E2 Theodolite, Surveying and Mapping, USA, 48 (1), 19-28.

Solarić, N., D. Špoljarić and Č. Nogić (1990). Analysis of the accuracy of the automatic azimuth determination by measuring zenith distances of star with electronic theodolite Kern E2, Hvar Obs. Bull. 14, 1990, 1-14

Solarić, N., and D. Špoljarić, (1992). Accuracy of the automatic astronomical azimuth determination by Polaris with Leica-Kern E2 electronic theodolite, Surveying and Land Information System, 2, 80-85.

Špoljarić, D. (2010). The basics of geodetic astronomy, lecture materials, University of Zagreb, Faculty of Geodesy, Zagreb, Croatia (in Croatian).

Špoljarić, D., and N. Solarić (2010). Automation of astrogeodetic measurements, Proceedings of the 10th International multidisciplinary scientific geoconference SGEM 2010, I, 837-844.

Šugar, D., M. Marjanović and Ž. Bačić (2009). The implementation of the CROPOS system in education at the Faculty of Geodesy, University of Zagreb, Proceedings of the 1st CROPOS conference, Croatian Geodetic Society, State Geodetic Administration, Zagreb, 87-104 (in Croatian).

Terzić, P. (1988). Geodetic astronomy II, University of Za- greb, Faculty of Geodesy, Zagreb, Croatia, 114-122 (in Croatian).

Terzić, P. (1990). Spherical astronomy, University of Zagreb, Faculty of Geodesy, Zagreb, Croatia, 314-327 (in Croatian).

Torge, W. (2001). Geodesy, Walter de Gruyter, Berlin/New York.

\footnotetext{
${ }^{\star}$ Corresponding author: Danijel Šugar, University of Zagreb, Faculty of Geodesy, Zagreb, Croatia; email: dsugar@geof.hr.
}

(C) 2012 by the Istituto Nazionale di Geofisica e Vulcanologia. All rights reserved. 